\title{
Phytochemical composition of crude extracts derived from Vernonia spp. and its larvicidal activity against Anopheles gambiae
}

\author{
BEATRICE TARWISH ${ }^{1, \vartheta}$, JOSEPH J. N. NGERANWA, ${ }^{2, \bullet}$, JOSPHAT C. MATASYOH ${ }^{3}$ \\ ${ }^{1}$ School of Pure and Applied Sciences, Kenyatta University. Nairobi, Kenya. \\ ${ }^{2}$ Department of Biochemistry and Biotechnology, Kenyatta University. Nairobi, Kenya. `email: ngeranwa.joseph@ku.ac.ke, ngeranwa@avu.org \\ ${ }^{3}$ Department of Chemistry, Egerton University. Nairobi, Kenya.
}

Manuscript received: 1 July 2017. Revision accepted: 14 November 2017.

\begin{abstract}
Tarwish B, Ngeranwa JJN, Matasyoh JC. 2017. Larvicidal activity and phytochemical composition of crude extracts derived from Vernonia spp. against Anopheles gambiae. Bonorowo Wetlands 7: 108-116. This study aimed to elucidate the larvicidal activity of three species of Vernonia, i.e., Vernonia lasiopus, V. auriculifera, and V. galamensis, against the malaria vector Anopheles gambiae. Dried samples from leaves and roots of the three plants were sequentially extracted with hexane, chloroform, ethyl acetate, acetone, methanol, and water. Following rotor evaporation of the solvents, the extracts were subjected to phytochemical analysis and larvicidal assays against the third instar larvae of A. gambiae. The phytochemical screening revealed the presence of steroids, saponins, flavonoids, terpenoids, and cardiac glycosides in all extracts. Tannins were present in methanol and water extracts of all three plants and acetone extract of $V$. lasiopus roots, V. auriculifera root, and V. galamensis leaf. Phlobatannins were absent in all extracts. Percent mortality for different concentrations $125,250,500,750$, and $1000 \mathrm{ppm}$ of the extracts was calculated and subsequently subjected to probit regression analysis to determine $\mathrm{LC}_{50}$ and $\mathrm{LC}_{90}$ values. The most active extract recorded was acetone root extract of $V$. galamensis with an $\mathrm{LC}_{50}$ of 22.85. Vernonia auriculifera and $V$. lasiopus recorded the highest activity in acetone root extract and ethyl acetate root extract with an $\mathrm{LC}_{50}$ value of 37.7 and 205.9, respectively. A one-Way ANOVA test was performed to compare the mean mortality of all tested groups. At all exposure hours except at 3 hours, the differences were significant. The Tukey post hoc tests indicated that the mortality rate for $V$. galamensis was substantially different from the mortality rates of $V$. lasiopus and $V$. auriculifera after 24 hours. This study underlines V. lasiopus, V. auriculifera, and V. galamensis as alternative sources of new, cheap, and readily available larvicides to control the mosquito vector A. gambiae. Further study is required to determine what secondary metabolites in Vernonia extracts are responsible for larvicidal activity.
\end{abstract}

Keywords: Anopheles gambiae, crude extracts, larvicidal activity, phytochemical composition, Vernonia

\section{INTRODUCTION}

Malaria has been widely known as one of the major diseases in the tropical and subtropical regions of the world. The coincidence of malaria is higher in poorer countries and mainly confined in the tropical areas of Asia, Africa, and Latin America. More than $90 \%$ of malaria cases and the majority of death caused by malaria occur in tropical Africa (Bell 2006). According to The Presidential Malaria Initiative (PMI 2014), about 70\% of the Kenyan population is at risk for malaria. WHO (2010) announced that the disease contributed to $20 \%$ of childhood death. While some diseases such as yellow fever have reasonably been brought under control by vaccination, unfortunately, the effective vaccine for malaria is still awaiting (Matasyoh et al., 2008). The efficacy of Mosquirix as a vaccine for malaria is being tested in phase 3 clinical trials. Early results show partial protection against malaria (Bejon 2013). Malaria is transmitted by mosquitoes carrying parasitic protozoans of the genus Plasmodium. The parasites are transmitted to humans by biting an infected female anopheline mosquito. In Africa, A. gambiae is the principal mosquito vector of malaria (Bockarie 2005).

One of the World Health Organization (WHO) strategies in combating tropical diseases is to demolish their vectors or intermediate hosts. Consequently, bioassays have become a preferred method to detect activities from traditional medicinal plant extract that could be used to prevent the transmission of four of the most common tropical diseases: malaria, schistosomiasis, dengue hemorrhagic fever, and yellow fever (Diallo 2001).

Continuous and indiscriminate synthetic insecticides have caused toxicity to non-target organisms and environmental pollution (Albuquerque 2007). Insect resistance to conventional insecticides stresses searching for new insecticides (Macedo et al. 1997). Secondary metabolites contribute towards the therapeutic value of plants, and when isolated from plants, they represent not only valuable drugs but also valuable lead molecules (Shrivastava and Patel 2007). Botanical insecticides are promising due to the nature of the compound that is potent, environmentally friendly, readily biodegradable, and inexpensive, too (Kalu et al., 2010).

The discovery of insecticidal activity of phytotoxins present in Asteraceae species has stimulated the search for new plant-derived insecticides, mainly from this plant's family (Macedo et al., 1997). The genus Vernonia is one of the primary sources of bioactive sesquiterpenoids, an important class of compounds due to their diverse biological activities (Magadula and Erasto 2009). Vernonia 
comprises about 1000 species in the family Asteraceae. They have intense purple flowers in South America, North America, Asia, and Africa.

Vernonia lasiopus grows on abandoned farmland, and a decoction of the leaves is locally used to cure stomach aches (Kokwaro 2009). Vernonia auriculifera grows on very fertile soils. It is abundant in the wet montane forest and beside lakes or streams (Oyen 2010). Local people use a concoction of the root to treat joint pains. Vernonia galamensis grows in highlands on sites where rainwater collects. It is native to East Africa and is produced in many parts of Ethiopia as an industrial oilseed. This investigation aimed to determine whether the three Vernonia species growing in Kenya, namely $V$. lasiopus, $V$. auriculifera, and $V$. galamensis, possess larvicidal activity against $A$. gambiae as a possible measure to control malaria.

The objectives of the study were (i) To determine the phytochemicals in organic extracts of $V$. lasiopus, $V$. auriculifera, and V. galamensis leaves and roots; (ii) To evaluate larvicidal activity of crude extracts from $V$. lasiopus, V. auriculifera, and $V$. galamensis against $A$. gambiae; (iii) To determine the $\mathrm{LC}_{50}$ and $\mathrm{LC}_{90}$ values of the crude extracts from $V$. lasiopus, $V$. auriculifera and $V$. galamensis against A. gambiae; (iv) To determine the effective concentration of the leaf and root extracts of $V$. lasiopus, $V$. auriculifera and $V$. galamensis against $A$. gambiae.

\section{MATERIALS AND METHODS}

\section{Collection and Identification of plant materials}

Vernonia lasiopus, V. auriculifera, and V. galamensis were identified from the Botanical garden of Egerton University in Njoro, Kenya, by a taxonomist from the Department of Botany in the University. Voucher specimens V. lasiopus (BT 1), V. auriculifera (BT 2), and V. galamensis (BT 3) were deposited at the Department of Biological Sciences, Egerton University, Kenya. Fresh aerial parts of the plants and roots were collected.

\section{Preparation of plant extracts}

The roots and fresh aerial parts of plant materials of $V$. lasiopus, V. auriculifera, and V. galamensis were dried separately under shade to achieve a constant weight and then ground to a fine powder. About $500 \mathrm{~g}$ of each powder was extracted sequentially with hexane $1.5 \mathrm{~L}$, chloroform $1.5 \mathrm{~L}$, ethyl acetate $1.5 \mathrm{~L}$, acetone $1.5 \mathrm{~L}$, methanol $1.5 \mathrm{~L}$, and water $1.5 \mathrm{~L}$ after soaking the sample in each solvent for three days. The extracts were run through a filter paper to obtain a homogenous solution. A thin layer of activated charcoal was added to the extracts from the aerial part of the plant samples to adsorb chlorophyll before filtering. The filtrates were then concentrated using a rotary evaporator to recover the solvent. The extracts were allowed to dry into a semi-solid state and subjected to phytochemical tests and larvicidal assays.

\section{Phytochemical analysis}

The extracts were analyzed for the presence of tannins, phlobatanins, saponins, flavonoids, steroids, terpenoids, and cardiac glycosides using standard procedures. A characteristic color change identified them.

Test for tannins. Two drops of $0.1 \%$ ferric chloride were added to $2 \mathrm{ml}$ of the extract. A brownish-green or blue, black coloration indicated a positive test (Trease and Evans 2002).

Test for phlobatannins. One milliliter of $1 \%$ aqueous $\mathrm{HCl}$ was added to $2 \mathrm{ml}$ of the extract and boiled. Deposition of a red precipitate indicated a positive test (Trease and Evans 2002).

Test for saponins. Before filtration, the extract $(1 \mathrm{~g})$ was boiled with $5 \mathrm{ml}$ of distilled water. Approximately 3 $\mathrm{ml}$ of distilled water was further added to the filtrate and shaken vigorously for 5 minutes. Frothing, which persisted in warming, was taken as evidence for the presence of saponins (Sofowora 1993).

Test for flavonoids. Extract ( $1 \mathrm{~g})$ was dissolved in ethanol, warmed up, and filtered. Three pieces of magnesium chips were added to the filtrate, followed by two drops of concentrated $\mathrm{HCl}$. A pink, orange, or red to purple coloration indicates the presence of flavonoids (Trease and Evans 2002).

Test for steroids. Two milliliters each of acetic anhydride and $\mathrm{H}_{2} \mathrm{SO}_{4}$ was added to about $2 \mathrm{ml}$ of extract. A change of color indicated the positive test from violet to blue or green (Sofowora 1993).

Test for terpenoids (Salkowski test). Extract ( $1 \mathrm{~g}$ ) was dissolved in ethanol. One milliliter of acetic anhydride was added, followed by concentrated $\mathrm{H}_{2} \mathrm{SO}_{4}$. A change in color from pink to violet showed the presence of terpenoids (Sofowora 1993).

Test for cardiac glycosides (Keller-Killiani test). Extract $(5 \mathrm{ml})$ was tested with $2 \mathrm{ml}$ of glacial acetic acid containing one drop of ferric chloride solution. One milliliter of concentrated $\mathrm{H}_{2} \mathrm{SO}_{4}$ was added slowly (underlay). The positive test was shown by a brown ring of the interface, which indicates the deoxy-sugar characteristic of cardenolides. The positive test was also suggested by the appearance of a violet ring below the brown ring. In contrast, in the acetic acid layer, a greenish ring formed gradually throughout the thin layer (Trease and Evans 2002).

\section{Anopheles gambiae larval culture}

Larvae of A. gambiae from the third instar were reared in the insectaries at the Kenya Medical Research Institute (KEMRI), Centre for Disease Control (CDC), Kisumu, Kenya, using a protocol for mosquito rearing obtained from (Das et al. 2007) with slight modifications. Male and female adult mosquitoes were kept in an insectary room for 4-5 days and were fed on 10\% sucrose solution. Mating occurred during this period. Four to five-day-old female mosquitoes were enclosed in a cage where a shaved rabbit was provided for the mosquitoes to acquire a blood meal by sucking the rabbit for about one hour. These females laid eggs two days after feeding on blood. A small filter paper wrapped in a conical shape was put in a bit of beaker 
containing water, ensuring the moistness of the filter paper. The beaker was kept inside the cage overnight, providing a place for the mosquitoes to lay eggs. The filter paper carrying the mosquito eggs was placed in a plastic tray with $300 \mathrm{ml}$ of spring river water. The eggs were kept at $26 \pm 3$ ${ }^{\circ} \mathrm{C}$ to be allowed to hatch to larvae within two to three days. Growing larvae were fed on tetramine fish food until they reached the third instar larvae. During this time, water on the tray was replaced every day, and a pinch of tetramine fish food was added to the water. On the $8^{\text {th }}$ day (5-day old larvae), the larvae population was diluted from one tray to 10 trays. A pinch of tetramine fish food was added to each tray. The third instar larvae emerged on day ten and were ready for bioassay experiments.

\section{Larvicidal assays}

The extracts were solubilized in Dimethyl-sulphoxide (DMSO) purchased from Lobarchemi and diluted with water to give $2000 \mathrm{ppm}$ of stock solution with DMSO kept at a concentration of $1 \%$. Serial dilution of different concentrations $(125,250,500,750$, and $1000 \mathrm{ppm})$ was prepared from the stock solution. The bioassay tests were carried out according to a standard WHO procedure (1981) with slight modifications. The bioassays occurred at the Kenya Medical Research Institute (KEMRI), Centre for Disease Control (CDC), Kisumu, Kenya. The insect larvae were reared in plastic and enamel trays spring river water. The larvae were maintained, and all experiments were carried out at $26 \pm 3^{\circ} \mathrm{C}$, with the humidity range between 70 to $75 \%$. The bioassays were done with third instar larvae of A. gambiae and examined in triplicate using 20 larvae for each replicate assay. The larvae were laid up in $50 \mathrm{ml}$ disposable plastic cups containing $15 \mathrm{ml}$ of the test solution and fed on tetramine fish feed during all testing periods. Larvae were considered dead if they were unresponsive, even when gently prodded. The dead larvae were counted at 3-hour intervals for 24 hours. The dead larvae in the three replicates were combined and expressed as the percentage mortality for each concentration. The negative control was $1 \%$ DMSO in spring river water, while the positive control was 100 ppm pyrethrum-based larvicide, pylarvex.

\section{Data analysis}

There was a significant difference between the means of the groups ( $V$. lasiopus, $V$. auriculifera, and $V$. galamensis) as determined by a one-way ANOVA. Nevertheless, a one-way ANOVA is an omnibus test statistic that can only tell that somewhere between the groups, a difference exists and cannot tell which specific groups were significantly different from each other. For this reason, the post hoc tests were run to confirm where the differences occurred between groups. Post hoc tests are executed when an overall significant difference in group means has already been established. Furthermore, Tukey's honestly significant difference (HSD) test is used as a post hoc test because it is less conservative than the Scheffe test (that means that you have a higher probability of detecting differences if they exist with Tukey's HSD test). The average mortality data of the larvae were also subjected to probit regression analysis based on the previous method
(Finney 1971) to estimate $\mathrm{LC}_{50}$ and $\mathrm{LC}_{90}$ values and associated $95 \%$ confidence limits. Probit analysis is a regression analysis used to analyze binomial response variables. It transforms the sigmoid dose-response curve to a straight line which can then be analyzed by regression through least squares or maximum likelihood. This analysis is commonly used in toxicology to determine the relative toxicology of chemicals to living organisms. The method is done by testing the response of an organism under various concentrations of each of the substances in question and then comparing the concentrations at which one encounters a reaction. The response is always binomial, and the relationship between the response and the various levels is still sigmoid. Probit analysis acts as a transformation from sigmoid to linear and then runs a regression on the link. The researcher can utilize the output of the probit analysis to compare the amount of the chemicals needed to create the same response in each of the various chemicals. Many endpoints are used to analyze the differing toxicities of compounds, but the $\mathrm{LC}_{50}$ (Liquid) and the $\mathrm{LD}_{50}$ (Solid) are the most widely used outcomes of the current doseresponse experiments. The $\mathrm{LC}_{50} / \mathrm{LD}_{50}$ defines the concentration $\left(\mathrm{LC}_{50}\right)$ and the dose $\left(\mathrm{LD}_{50}\right)$ at which $50 \%$ of the population responds. Statistical Package for the Social Sciences (SPSS) software version 19 (IBM) was used for data analysis.

\section{RESULTS AND DISCUSSION}

\section{Phytochemical compounds in Vernonia extracts}

Both leaves and roots from three Vernonia plant extracts contained almost similar compounds. The results obtained from phytochemical tests are given in (Table 1). The data for the phytochemical screening of V. lasiopus, $V$. auriculifera, and V. galamensis extracts (Table 1) revealed the presence of steroids, flavonoids, saponins, terpenoids, and cardiac glycosides. Tannins were present in the methanol and water extracts of the three plants and acetone extracts of $V$. lasiopus root, $V$. auriculifera root, and $V$. galamensis leaf. However, phlobatannins were absent in all extracts.

\section{Results of larvicidal activity}

The larvicidal activity of hexane, chloroform, ethyl acetate, acetone, methanol, and water extracts of the leaves and roots of $V$. auriculifera, $V$. lasiopus, and $V$. galamensis revealed that all the tested extracts were active against the larvae of A. gambiae except the water extracts. Data of the larvicidal activity of the extracts against A. gambiae are presented in (Table 2). In the negative control, no mortality was detected of $1 \%$ DMSO in spring river water.

A one-Way ANOVA test was done to compare the means of the groups ( $V$. lasiopus, $V$. auriculifera, $V$. galamensis). The results are recorded in (Table 3). The differences were significantly different at all hours except at 3 hours as determined by one-way ANOVA (Table 3). For each significant test, Post-hoc Tukey's HSD tests were done to determine which two pairs differed significantly, and the results were shown in the tables below. 
Table 1. Phytochemical compounds present in Vernonia plant extracts from leaf and root using different solvents

\begin{tabular}{|c|c|c|c|c|c|c|c|c|c|c|c|c|c|}
\hline Fraction & Species & & & Le & & & & & & & & & \\
\hline & & Hexane & EtOAc & $\mathrm{CHCl}_{3}$ & Acetone & $\mathrm{MeOH}$ & Water & Hexane & EtOA & $\mathrm{CHCl}_{3}$ & Acetone & $\mathrm{MeOH}$ & Water \\
\hline Tannins & V. lasiopus & - & - & - & - & + & + & - & - & - & + & + & + \\
\hline & V. auriculifera & - & - & - & - & + & + & - & - & - & + & + & + \\
\hline & V. galamensis & - & - & - & + & + & + & - & - & - & - & + & + \\
\hline Phlobatanins & V. lasiopus & - & - & - & - & - & - & - & - & - & - & - & - \\
\hline & V. auriculifera & - & - & - & - & - & - & - & - & - & - & - & - \\
\hline & V. galamensis & - & - & - & - & - & - & - & - & - & - & - & - \\
\hline Saponin & V. lasiopus & + & + & + & + & + & + & + & + & + & + & + & + \\
\hline & V. auriculifera & + & + & + & + & + & + & + & + & + & + & + & + \\
\hline & V. galamensis & + & + & + & + & + & + & + & + & + & + & + & + \\
\hline Flavonoids & V. lasiopus & + & + & + & + & + & + & + & + & + & + & + & + \\
\hline & V. auriculifera & + & + & + & + & + & + & + & + & + & + & + & + \\
\hline & V. galamensis & + & + & + & + & + & + & + & + & + & + & + & + \\
\hline Steroids & V. lasiopus & + & + & + & + & + & + & + & + & + & + & + & + \\
\hline & V. auriculifera & + & + & + & + & + & + & + & + & + & + & + & + \\
\hline & V. galamensis & + & + & + & + & + & + & + & + & + & + & + & + \\
\hline Terpenoids & V. lasiopus & + & + & + & + & + & + & + & + & + & + & + & + \\
\hline & V. auriculifera & + & + & + & + & + & + & + & + & + & + & + & + \\
\hline & V. galamensis & + & + & + & + & + & + & + & + & + & + & + & + \\
\hline Cardiac & V. lasiopus & + & + & + & + & + & + & + & + & + & + & + & + \\
\hline glycosides & V. auriculifera & + & + & + & + & + & + & + & + & + & + & + & + \\
\hline & V. galamensis & + & + & + & + & + & + & + & + & + & + & + & + \\
\hline
\end{tabular}

Note: + present, - absent

The Tukey post hoc tests indicated that the mortality rate for $V$. galamensis (mean $=1.47$ ) was significantly different from the rate of the mortality of $V$. lasiopus (mean $=0.66)$ and $V$. auriculifera $($ mean $=0.79)$. However, there is no significant difference between $V$. lasiopus (mean $=$ $0.66)$ and $V$. auriculifera $($ mean $=0.79)$. This pattern was maintained at all hours, with the final recording made at 24 hours, as shown in (Table 4).

On a similar note, the Tukey post hoc tests showed that $V$. galamensis mortality rate (mean $=4.08$ ) was significantly different from that of $V$. lasiopus (mean $=$ $2.16)$ and $V$. auriculifera $($ mean $=2.41)$.

Additionally, based on Tukey post hoc tests, the mortality rate for $V$. galamensis (mean $=6.62$ ) was significantly different from the mortality rates of $V$. lasiopus $($ mean $=4.02)$ and $V$. auriculifera $($ mean $=4.23)$.

The Tukey post hoc tests suggested that the mortality rate for $V$. galamensis (mean $=7.73$ ) was significantly different from that of $V$. lasiopus (mean $=5.29$ ) and $V$. auriculifera $($ mean $=5.57)$.

The Tukey post hoc tests gave the following results, as shown in (Table 5).

The Tukey post hoc tests demonstrated that the mortality rate for $V$. lasiopus (mean $=0.50$ ) and $V$. auriculifera (mean $=0.19$ ) were significantly different from the mortality rate for V.galamensis $($ mean $=1.23)$. This pattern was replicated for hours $9,12,15$, and 18, as shown in (Table 5) after which the trend changed.

The Tukey post hoc tests showed that the mortality rate for $V$. galamensis $($ mean $=4.84)$ was significantly different from the counterparts of $V$. auriculifera $($ mean $=1.91)$. Yet, the mortality rate for $V$. lasiopus (mean $=3.40$ ) is neither significantly different from that of $V$. galamensis nor $V$. auriculifera. The same pattern was maintained at hour 24, as shown in (Table 5).

When all the root extracts were analyzed, The Tukey post hoc tests indicated significant differences between the means of groups ( $V$. lasiopus, $V$. auriculifera, and $V$. galamensis) as recorded in (Table 6).

The Tukey post hoc result showed that the mortality rate between $V$. lasiopus $($ mean $=0.82)$ and $V$. galamensis (mean $=1.71)$ was significantly different. However, the mortality rate for $V$. auriculifera (mean $=1.40$ ), on the other hand, was not substantially different from neither $V$. lasiopus nor $V$. galamensis. This pattern was replicated for hours 9, 12, 15, and 18, as shown in (Table 6).

When extracts of various solvents were analyzed, acetone extracts of root and leaf showed significant differences between the means of $\mathrm{V}$. lasiopus, $\mathrm{V}$. auriculifera, and V. galamensis (Table 7).

When acetone was used for roots extraction, the Tukey post hoc tests indicated that the mortality rate for the three plants was significantly different from each other. The differences were found to be significantly different between any two plants, V. galamensis $($ mean $=19.47), V$. auriculifera $($ mean $=16.87)$, and $V$. lasiopus $($ mean $=$ 5.29).

At hour 24, the Tukey post hoc tests indicated the mortality rate of acetone extract of the leaves for $V$. lasiopus $($ mean $=6.60)$ and $V$. auriculifera $($ mean $=6.07)$ was not statistically different. Yet, the two means were statistically different from the mean of $V$. galamensis $($ mean $=17.53)$.

The larvicidal activity of $V$. lasiopus, $V$. auriculifera, and V. galamensis (Table 8) was determined by probit analysis as estimates of lethal concentration that kills $50 \%$ $\left(\mathrm{LC}_{50}\right)$ and $90 \%\left(\mathrm{LC}_{90}\right)$ of the exposed larvae respectively and their associated $95 \%$ confidence interval. 
Table 2. Mean mortality and the standard deviation of A. gambiae larvae exposed to root and leaf extracts of $V$. Auriculifera, $V$. galamensis, and $V$. lasiopus

\begin{tabular}{|c|c|c|c|c|c|c|c|c|c|c|}
\hline Plant & Solvent & & $3 \mathrm{hrs}$ & 6hrs & 9hrs & $12 \mathrm{hrs}$ & $15 \mathrm{hrs}$ & $18 \mathrm{hrs}$ & $21 \mathrm{hrs}$ & $24 \mathrm{hrs}$ \\
\hline V. auriculifera & $\begin{array}{l}\text { Acetone } \\
\text { Chloroform } \\
\text { Ethyl acetate } \\
\text { Hexane } \\
\text { Methanol } \\
\text { Water } \\
\text { Total }\end{array}$ & $\begin{array}{l}\text { Mean } \\
\text { N } \\
\text { SD } \\
\text { Mean } \\
\text { N } \\
\text { SD } \\
\text { Mean } \\
\text { N } \\
\text { SD } \\
\text { Mean } \\
\text { N } \\
\text { SD } \\
\text { Mean } \\
\text { N } \\
\text { SD } \\
\text { Mean } \\
\text { N } \\
\text { SD } \\
\text { Mean } \\
\text { N } \\
\text { SD }\end{array}$ & $\begin{array}{l}.20 \\
30 \\
.484 \\
.03 \\
30 \\
.183 \\
.70 \\
30 \\
3.650 \\
.00 \\
30 \\
.000 \\
.00 \\
30 \\
.000 \\
.00 \\
30 \\
.000 \\
.16 \\
180 \\
1.505\end{array}$ & $\begin{array}{l}1.93 \\
30 \\
2.067 \\
1.57 \\
30 \\
2.738 \\
1.23 \\
30 \\
1.870 \\
.00 \\
30 \\
.000 \\
.03 \\
30 \\
.183 \\
.00 \\
30 \\
.000 \\
.79 \\
180 \\
1.771\end{array}$ & $\begin{array}{l}3.67 \\
30 \\
3.231 \\
2.73 \\
30 \\
4.362 \\
2.17 \\
30 \\
3.217 \\
.00 \\
30 \\
.000 \\
.17 \\
30 \\
.531 \\
.00 \\
30 \\
.000 \\
1.46 \\
180 \\
2.943\end{array}$ & $\begin{array}{l}5.67 \\
30 \\
4.205 \\
4.33 \\
30 \\
6.456 \\
3.73 \\
30 \\
5.119 \\
.00 \\
30 \\
.000 \\
.73 \\
30 \\
.907 \\
.00 \\
30 \\
.000 \\
2.41 \\
180 \\
4.371\end{array}$ & $\begin{array}{l}7.37 \\
30 \\
5.623 \\
6.47 \\
30 \\
8.476 \\
4.97 \\
30 \\
6.708 \\
.00 \\
30 \\
.000 \\
1.70 \\
30 \\
1.643 \\
.00 \\
30 \\
.000 \\
3.42 \\
180 \\
5.786\end{array}$ & $\begin{array}{l}9.13 \\
30 \\
5.698 \\
6.67 \\
30 \\
8.535 \\
7.20 \\
30 \\
8.540 \\
.00 \\
30 \\
.000 \\
2.37 \\
30 \\
2.141 \\
.00 \\
30 \\
.000 \\
4.23 \\
180 \\
6.535\end{array}$ & $\begin{array}{l}10.93 \\
30 \\
6.416 \\
6.77 \\
30 \\
8.553 \\
8.47 \\
30 \\
9.012 \\
.00 \\
30 \\
.000 \\
3.23 \\
30 \\
3.491 \\
.00 \\
30 \\
.000 \\
4.90 \\
180 \\
7.140\end{array}$ & $\begin{array}{l}11.47 \\
30 \\
6.329 \\
7.73 \\
30 \\
8.558 \\
8.80 \\
30 \\
9.118 \\
.00 \\
30 \\
.000 \\
3.77 \\
30 \\
3.520 \\
.00 \\
30 \\
.000 \\
5.29 \\
180 \\
7.284\end{array}$ \\
\hline V. galamensis & $\begin{array}{l}\text { Acetone } \\
\text { Chloroform } \\
\text { Ethyl acetate } \\
\text { Hexane } \\
\text { Methanol } \\
\text { Water } \\
\text { Total }\end{array}$ & $\begin{array}{l}\text { Mean } \\
\text { N } \\
\text { SD } \\
\text { Mean } \\
\text { N } \\
\text { SD } \\
\text { Mean } \\
\text { N } \\
\text { SD } \\
\text { Mean } \\
\text { N } \\
\text { SD } \\
\text { Mean } \\
\text { N } \\
\text { SD } \\
\text { Mean } \\
\text { N } \\
\text { SD } \\
\text { Mean } \\
\text { N } \\
\text { SD }\end{array}$ & $\begin{array}{l}.43 \\
30 \\
.626 \\
.10 \\
30 \\
.403 \\
.00 \\
30 \\
.000 \\
.13 \\
30 \\
.507 \\
.00 \\
30 \\
.000 \\
.00 \\
30 \\
.000 \\
.11 \\
180 \\
.394\end{array}$ & $\begin{array}{l}5.87 \\
30 \\
3.421 \\
1.23 \\
30 \\
1.888 \\
1.60 \\
30 \\
1.993 \\
.13 \\
30 \\
.507 \\
.00 \\
30 \\
.000 \\
.00 \\
30 \\
.000 \\
1.47 \\
180 \\
2.727\end{array}$ & $\begin{array}{l}9.27 \\
30 \\
2.690 \\
2.67 \\
30 \\
3.642 \\
3.03 \\
30 \\
3.368 \\
.47 \\
30 \\
1.008 \\
.00 \\
30 \\
.000 \\
.00 \\
30 \\
.000 \\
2.57 \\
180 \\
3.979\end{array}$ & $\begin{array}{l}13.53 \\
30 \\
3.256 \\
4.23 \\
30 \\
5.734 \\
4.77 \\
30 \\
4.939 \\
1.40 \\
30 \\
2.094 \\
.53 \\
30 \\
1.634 \\
.00 \\
30 \\
.000 \\
4.08 \\
180 \\
5.771\end{array}$ & $\begin{array}{l}17.20 \\
30 \\
3.755 \\
6.50 \\
30 \\
8.936 \\
5.87 \\
30 \\
6.196 \\
2.23 \\
30 \\
3.287 \\
1.30 \\
30 \\
2.867 \\
.00 \\
30 \\
.000 \\
5.52 \\
180 \\
7.581\end{array}$ & $\begin{array}{l}17.97 \\
30 \\
3.189 \\
6.77 \\
30 \\
8.943 \\
10.20 \\
30 \\
8.252 \\
2.93 \\
30 \\
4.201 \\
1.87 \\
30 \\
3.655 \\
.00 \\
30 \\
.000 \\
6.62 \\
180 \\
8.234\end{array}$ & $\begin{array}{l}18.27 \\
30 \\
2.947 \\
6.83 \\
30 \\
8.906 \\
11.20 \\
30 \\
8.062 \\
3.77 \\
30 \\
4.925 \\
2.80 \\
30 \\
4.874 \\
.00 \\
30 \\
.000 \\
7.14 \\
180 \\
8.349\end{array}$ & $\begin{array}{l}18.50 \\
30 \\
2.862 \\
7.60 \\
30 \\
8.609 \\
12.27 \\
30 \\
7.939 \\
4.27 \\
30 \\
5.298 \\
3.77 \\
30 \\
5.418 \\
.00 \\
30 \\
.000 \\
7.73 \\
180 \\
8.390\end{array}$ \\
\hline V. lasiopus & $\begin{array}{l}\text { Acetone } \\
\text { Chloroform } \\
\text { Ethyl acetate } \\
\text { Hexane } \\
\text { Methanol } \\
\text { Water }\end{array}$ & $\begin{array}{l}\text { Mean } \\
\text { N } \\
\text { SD } \\
\text { Mean } \\
\text { N } \\
\text { SD } \\
\text { Mean } \\
\text { N } \\
\text { SD } \\
\text { Mean } \\
\text { N } \\
\text { SD } \\
\text { Mean } \\
\text { N } \\
\text { SD } \\
\text { Mean } \\
\text { N } \\
\text { SD } \\
\text { Mean } \\
\text { N } \\
\text { SD }\end{array}$ & $\begin{array}{l}.17 \\
30 \\
.461 \\
.07 \\
30 \\
.254 \\
.00 \\
30 \\
.000 \\
.00 \\
30 \\
.000 \\
.00 \\
30 \\
.000 \\
.00 \\
30 \\
.000 \\
.04 \\
180 \\
.221\end{array}$ & $\begin{array}{l}.50 \\
30 \\
.900 \\
2.33 \\
30 \\
4.020 \\
.93 \\
30 \\
1.413 \\
.00 \\
30 \\
.000 \\
.20 \\
30 \\
.664 \\
.00 \\
30 \\
.000 \\
.66 \\
180 \\
1.952\end{array}$ & $\begin{array}{l}1.17 \\
30 \\
1.642 \\
3.87 \\
30 \\
5.097 \\
1.97 \\
30 \\
2.341 \\
.27 \\
30 \\
.980 \\
.40 \\
30 \\
1.102 \\
.00 \\
30 \\
.000 \\
1.28 \\
180 \\
2.769\end{array}$ & $\begin{array}{l}1.97 \\
30 \\
2.109 \\
5.83 \\
30 \\
6.894 \\
3.07 \\
30 \\
3.704 \\
.87 \\
30 \\
2.047 \\
1.23 \\
30 \\
2.112 \\
.00 \\
30 \\
.000 \\
2.16 \\
180 \\
3.957\end{array}$ & $\begin{array}{l}2.60 \\
30 \\
2.513 \\
7.00 \\
30 \\
7.991 \\
4.53 \\
30 \\
5.643 \\
1.10 \\
30 \\
2.383 \\
1.63 \\
30 \\
1.921 \\
.00 \\
30 \\
.000 \\
2.81 \\
180 \\
4.852\end{array}$ & $\begin{array}{l}3.47 \\
30 \\
2.763 \\
7.37 \\
30 \\
8.122 \\
9.27 \\
30 \\
8.337 \\
1.53 \\
30 \\
2.825 \\
2.47 \\
30 \\
3.003 \\
.00 \\
30 \\
.000 \\
4.02 \\
180 \\
6.052\end{array}$ & $\begin{array}{l}4.40 \\
30 \\
3.654 \\
7.70 \\
30 \\
8.322 \\
10.73 \\
30 \\
8.725 \\
1.90 \\
30 \\
3.166 \\
5.33 \\
30 \\
6.375 \\
.00 \\
30 \\
.000 \\
5.01 \\
180 \\
6.822\end{array}$ & $\begin{array}{l}4.93 \\
30 \\
4.076 \\
8.30 \\
30 \\
8.730 \\
11.30 \\
30 \\
8.864 \\
2.67 \\
30 \\
3.968 \\
6.20 \\
30 \\
6.435 \\
.00 \\
30 \\
.000 \\
5.57 \\
180 \\
7.108\end{array}$ \\
\hline
\end{tabular}

Table 3. One-Way ANOVA test results showing the level of significance at a 3-hour interval

\begin{tabular}{lcccccccc}
\hline Hour & $\mathbf{3}$ & $\mathbf{6}$ & $\mathbf{9}$ & $\mathbf{1 2}$ & $\mathbf{1 5}$ & $\mathbf{1 8}$ & $\mathbf{2 1}$ & $\mathbf{2 4}$ \\
\hline $\mathrm{F}(2,537)$ & 0.758 & 7.102 & 8.267 & 8.614 & 9.510 & 7.687 & 5.167 & 5.544 \\
p-value & 0.469 & 0.001 & 0.001 & 0.000 & 0.000 & 0.001 & 0.006 & 0.004 \\
\hline
\end{tabular}


Table 4. Total mean mortality rates of all extracts after

\begin{tabular}{lccc}
\hline Plant name & $\mathbf{N}$ & \multicolumn{2}{c}{ Subset for alpha $=\mathbf{0 . 0 5}$} \\
\cline { 3 - 4 } & & $\mathbf{1}$ & $\mathbf{2}$ \\
\hline 6 hours & & & \\
V. auriculifera & 90 & 0.66 & \\
V. lasiopus & 90 & 0.79 & 1.47 \\
V. galamensis & 90 & &
\end{tabular}

\section{2 hours}

$\begin{array}{lll}V . \text { auriculifera } & 90 & 2.16 \\ \text { V. lasiopus } & 90 & 2.41\end{array}$

V. galamensi

90

.41

18 hours

$\begin{array}{lll}V . \text { auriculifera } & 90 & 4.02 \\ \text { V. lasiopus } & 90 & 4.23 \\ \text { V. } \text { galamensis } & 90 & \end{array}$

V. galamensis

90

.23

\section{4 hours}

V. auriculifera

V. lasiopus

V. galamensis

$\begin{array}{ll}90 & 5.29 \\ 90 & 5.57\end{array}$

5.29
5.57

90

7.73

Table 5. Total mean mortality rates of all leaf extracts of Vernonia spp.

\begin{tabular}{lccc}
\hline Plant name & $\mathbf{N}$ & \multicolumn{2}{c}{ Subset for alpha $=\mathbf{0 . 0 5}$} \\
$\mathbf{1}$ & $\mathbf{2}$ \\
\hline 6 hours & & & \\
$\quad$ V. auriculifera & 90 & 0.19 & \\
V. lasiopus & 90 & 0.50 & 1.23 \\
V. galamensis & 90 & &
\end{tabular}

\section{9 hours}

V. auriculifera

V. lasiopus

90

0.36

V. galamensis

90

0.87

\section{2 hours}

$\begin{array}{lll}\text { V. auriculifera } & 90 & 0.64 \\ \text { V. lasiopus } & 90 & 1.32 \\ \text { V. galamensis } & 90 & \end{array}$

\section{5 hours}

$\begin{array}{lll}\text { V. auriculifera } & 90 & 0.99 \\ \text { V. lasiopus } & 90 & 1.59 \\ \text { V. galamensis } & 90 & \end{array}$

\section{8 hours}

$\begin{array}{lll}\text { V. auriculifera } & 90 & 1.69 \\ \text { V. lasiopus } & 90 & 2.54 \\ \text { V. galamensis } & 90 & \end{array}$

\section{1 hours}

$\begin{array}{lll}\text { V. auriculifera } & 90 & 1.91 \\ \text { V. lasiopus } & 90 & 3.40 \\ \text { V. galamensis } & 90 & \end{array}$

\section{4 hours}

\begin{tabular}{llll}
24 hours & & & \\
V. auriculifera & 90 & 2.42 & \\
V. lasiopus & 90 & 3.90 & 5.58 \\
V. galamensis & 90 & & \\
\hline
\end{tabular}

Table 6. Total mean mortality rates of all root extracts

\begin{tabular}{llll}
\hline Plant name & $\mathbf{N}$ & \multicolumn{2}{c}{$\begin{array}{l}\text { Subset for alpha }=\mathbf{0 . 0 5} \\
\mathbf{1}\end{array}$} \\
\hline 6 hours & & & \\
$\quad$ V. auriculifera & 90 & 0.82 & \\
V. lasiopus & 90 & 1.40 & 1.71 \\
$\quad$ V. galamensis & 90 & &
\end{tabular}

\section{9 hours}

$\begin{array}{lll}V . \text { auriculifera } & 90 & 1.69 \\ V . \text { lasiopus } & 90 & 2.56 \\ V . \text { galamensis } & 90 & \end{array}$

\section{2 hours}

$\begin{array}{llll}V . \text { auriculifera } & 90 & 3.00 & \\ \text { V. lasiopus } & 90 & 4.18 & \\ \text { V. galamensis } & 90 & & 5.36\end{array}$

\section{5 hours}

$\begin{array}{lll}V . & \text { lasiopus } \quad 90 & 4.03\end{array}$

$V$. auriculifera $\quad 90 \quad 5.84$

$\begin{array}{lll}V \text { galamensis } & 90 & 7.39\end{array}$

\begin{tabular}{llll}
18 hours & & & \\
V. lasiopus & 90 & 5.49 & \\
V. auriculifera & 90 & 6.77 & 8.97 \\
V. galamensis & 90 & & \\
\hline
\end{tabular}

Table 7. Total mean mortality rates of all root and leaf extracts of acetone after 24 hours

\begin{tabular}{|c|c|c|c|}
\hline \multirow[t]{2}{*}{ Plant name } & \multirow[t]{2}{*}{$\mathbf{N}$} & \multicolumn{2}{|c|}{ Subset for alpha $=0.05$} \\
\hline & & 1 & 3 \\
\hline \multicolumn{4}{|l|}{ Root extracts } \\
\hline V. lasiopus & 15 & 3.27 & \\
\hline V. auriculifera & 15 & 16.87 & \\
\hline$V$. galamensis & 15 & & 19.47 \\
\hline \multicolumn{4}{|l|}{ Leaf extracts } \\
\hline V. auriculifera & 15 & 6.07 & \\
\hline V. lasiopus & 15 & 6.60 & \\
\hline V. galamensis & 15 & 17.53 & \\
\hline
\end{tabular}

Table 9. Effective concentration of $V$. auriculifera, $V$. galamensis, and $V$. lasiopus extracts against $A$. gambiae

\begin{tabular}{lll}
\hline Plant & Part & Effective concentration \\
\hline$V$. auriculifera & Leaf & None \\
$V$. auriculifera & Root & $1000 \mathrm{ppm}$ \\
$V$. galamensis & Leaf & None \\
$V$. galamensis & Root & $500 \mathrm{ppm}$ and above \\
$V$. lasiopus & Leaf & $1000 \mathrm{ppm}$ \\
V. lasiopus & Root & $1000 \mathrm{ppm}$ \\
\hline
\end{tabular}


Table 8. Estimates of $\mathrm{LC}_{50}$ and $\mathrm{LC}_{90}$ values of $V$. Lasiopus, $V$. auriculifera, and $V$. galamensis extracts from the root and leaf with different solvents against $A$. gambiae and their associated $95 \%$ confidence interval

\begin{tabular}{|c|c|c|c|}
\hline Solvent & Part & $\begin{array}{l}\mathrm{LC}_{50}(\mathrm{ppm}) \text { and } 95 \% \\
\text { confidence interval }\end{array}$ & $\begin{array}{l}\text { LC90 (ppm)and95\% } \\
\text { confidence interval }\end{array}$ \\
\hline \multicolumn{4}{|l|}{ V. lasiopus } \\
\hline \multirow[t]{2}{*}{ Hexane } & Leaf & $1730.4(753.7-2707.2)$ & $2306.9(520.1-4093.6)$ \\
\hline & Root & $966.6(790.0-1143.2)$ & $1469.6(1039.3-1899.9)$ \\
\hline \multirow{2}{*}{ Chloroform } & Leaf & $872.9(820.2-925.6)$ & $997.9(918.2-1077.6)$ \\
\hline & Root & $309.9(273.8-346.0)$ & $405.4(355.3-455.0)$ \\
\hline \multirow{2}{*}{ Ethyl acetate } & Leaf & $622.9(574.6-671.3)$ & $748.3(685.1-811.4)$ \\
\hline & Root & $205.9(179.2-232.6)$ & $276.63(239.4-313.8)$ \\
\hline \multirow[t]{2}{*}{ Acetone } & Leaf & 1108 (554.9-1661.0) & $3744.7(1813.2-7308.1)$ \\
\hline & Root & $1285.5(907.6-1663.5)$ & $2012.2(1087.6-2936.8)$ \\
\hline \multirow[t]{2}{*}{ Methanol } & Leaf & $2247.1(376.9-4117.3)$ & $7176.4(-2807.6-17161)$ \\
\hline & Root & $577.6(517.9-637.3)$ & $767.94(677.17-858.71)$ \\
\hline \multirow[t]{2}{*}{ Water } & Leaf & 0.0 & 0.0 \\
\hline & Root & 0.0 & 0.0 \\
\hline \multicolumn{4}{|l|}{ V. auriculifera } \\
\hline \multirow[t]{2}{*}{ Hexane } & Leaf & 0.0 & 0.0 \\
\hline & Root & 0.0 & 0.0 \\
\hline \multirow[t]{2}{*}{ Chloroform } & Leaf & $1095.3(905.5-1285.1)$ & $1466.6(1066.1-1867.0)$ \\
\hline & Root & $314.4(278.7-350.1)$ & $406.0(357.4-454.6)$ \\
\hline \multirow[t]{2}{*}{ Ethyl acetate } & Leaf & $2246.1(355.1-4116.3)$ & $7174.0(-2807-17160)$ \\
\hline & Root & $198.0(175.4-220.6)$ & $250.0(219.6-280.3)$ \\
\hline \multirow[t]{2}{*}{ Acetone } & Leaf & $1730.3(752.7-2706.2)$ & $2306.9(752.7-4093.6)$ \\
\hline & Root & $37.7(15.0-60.4)$ & $148.4(81.1-215.8)$ \\
\hline \multirow[t]{2}{*}{ Methanol } & Leaf & $1494.0(873.1-2114.9)$ & $2713.4(944.3-4482.5)$ \\
\hline & Root & $1824.7(634.0-3015.5)$ & $4836.2(4129.3-10085)$ \\
\hline \multirow[t]{2}{*}{ Water } & Leaf & 0.0 & 0.0 \\
\hline & Root & 0.0 & 0.0 \\
\hline \multicolumn{4}{|l|}{ V. galamensis } \\
\hline \multirow[t]{2}{*}{ Hexane } & Leaf & $959.5(848.5-1070.4)$ & $1227.1(1005.0-1449.1)$ \\
\hline & Root & $814.0(746.2-881.8)$ & $1005.6(889.7-1121.6)$ \\
\hline \multirow[t]{2}{*}{ Chloroform } & Leaf & $1339.39(943.3-1844.5)$ & $2040.5(1043.0-3038.0)$ \\
\hline & Root & $293.4(267.4-319.5)$ & $338.1(300.5-375.7)$ \\
\hline \multirow[t]{2}{*}{ Ethyl Acetate } & Leaf & $735.0(661.0-809.1)$ & $972.5(839.4-1105.7)$ \\
\hline & Root & $68.2(33.06-103.4)$ & $114.1(375.0-153.1)$ \\
\hline \multirow[t]{2}{*}{ Acetone } & Leaf & $62.6(28.7-96.5)$ & $139.2(88.7-189.7)$ \\
\hline & Root & $22.8(5.82-39.8)$ & $45.3(17.9-72.7)$ \\
\hline \multirow[t]{2}{*}{ Methanol } & Leaf & $105587(-365501-576676)$ & $2623534(-15360000-20609746)$ \\
\hline & Root & $15368(-22676-53413)$ & $129930(-370638-630498)$ \\
\hline \multirow{2}{*}{ Water } & Leaf & 0.0 & 0.0 \\
\hline & Root & 0.0 & 0.0 \\
\hline
\end{tabular}

The most active extracts recorded were $V$. galamensis acetone root extract, acetone leaf extract, and ethyl acetate root extract with $\mathrm{LC}_{50}$ values of $22.85,62.61$, and 68.24 , respectively. Ethyl acetate root extracts were the most active extract of $V$. lasiopus, with an $\mathrm{LC}_{50}$ value of 205.9 . Vernonia lasiopus recorded an $\mathrm{LC}_{50}$ value of 37.7 in acetone root extract as its most active extract.

Since effective concentration was assumed to be any concentration that kills at least $50 \%$ of the exposed larva of A. gambiae, Table 9 shows the sufficient concentration for $V$. auriculifera root extracts and V. lasiopus root and leaf extracts were $1000 \mathrm{ppm}$. In contrast, the effective concentration for $V$. galamensis root extracts was $500 \mathrm{ppm}$ and above. Extracts of $V$. galamensis and $V$. auriculifera leaf extracts did not have an effective concentration of 125 ppm to $1000 \mathrm{ppm}$.

\section{Discussion}

Phytochemical screening of $V$. lasiopus, $V$. auriculifera, and $V$. galamensis extracts revealed the presence of steroids, saponins, flavonoids, terpenoids, and cardiac glycosides. Tannins could be extracted with methanol from the three plants and acetone from $V$. lasiopus root, $V$. auriculifera root, and $V$. galamensis leaf. However, phlobatannins were absent in all extracts (Table 1). This study suggested extracts from the three Vernonia plants possess larvicidal activity against Anopheles gambiae. Their activity was significantly different at all hours except at 3 hours exposure as determined by one-way ANOVA. The activity of crude plant extracts is attributed to the complex mixture of active compounds. We suggest that the bioactivity of the extracts observed here could be due to the phytochemicals detected, which have been reported in an 
earlier study to be responsible for mosquito larvicidal activity. Most studies have reported active insecticidal compounds like saponins, tannins, terpenoids, flavonoids, and steroids. Several plants of the Asteraceae family are said to have mosquito larvicidal activity due to the presence of several flavonoids (Srivastava et al., 2008). Steroid compounds are responsible for mosquito larval toxicity (Chowdhury et al., 2008). Saponin is well known as a potential mosquito larvicidal compound. It works by interacting with the cuticle membrane of the larva, ultimately disconnecting the membrane, which is the most plausible reason for larval death (Bayavan 2008; Chowdhury et al. 2008).

The difference in the activity of the extracts could be attributed to the different concentrations of phytochemicals in the extracts. The bioactivities demonstrated by the various extracts may also be attributed to the uneven distribution of chemical constituents within these extracts. When used in their crude form, the phytochemicals could have exhibited synergistic or additive effects (Mohamed et al., 2010). Secondary compounds of plants may jointly or independently have activity against mosquito targets from their ovicidal, pupicidal, activity against the adult, and inhibition of growth activity (Borah et al., 2010).

The primary target of insecticides includes the nervous system, endocrine, and metabolic processes. Metabolic processes are inhibited by disrupting the cell membrane and mechanical suffocation. Inhibition of metabolic pathways such as electron transport and oxidative phosphorylation disrupts energy production leading to death. Other insecticides, e.g., organophosphates, cause overstimulation of the nervous system leading to paralysis and death. The chemicals might achieve this effect by inhibiting cholinesterase activity or acting as sodium channel modulators (Brown 2006). Insect growth regulators (IGRs) attack the insect's endocrine system, which produces the hormones needed for growth and development into the adult form. Insects poisoned with IGRs cannot molt or reproduce, and they eventually die since hormones play various roles in molting (Elsheikha and Khan 2011). Disturbance of or interference with any of these hormones suppressed the molting process. Different insecticides target insect growth and development by interfering with hormones and others by preventing the production of a structural component of the exoskeleton. Some insecticides called Chitin Synthesis Inhibitors (CSI) inhibit the production of chitin. An insect poisoned with a CSI cannot produce chitin and thus cannot molt. Since molting must occur for the insect to reach the adult stage, a CSI poisoned insect cannot reproduce (Brown 2006). The mortality obtained in all the extracts may be due to any of these effects brought by the presence of active chemical compounds.

The larvicidal activity was observed at 3-hour intervals for 24 hours. No mortality was seen in the controls. Extracts from hexane, chloroform, ethyl acetate, acetone, and methanol showed a moderate toxic effect on $A$. gambiae after 24 hours of exposure. Ethyl acetate, chloroform, and acetone exhibited more significant activity than the least polar hexane extract and the more polar extract methanol. Water extracts as the most polar solvent showed no activity. Higher activity in ethyl acetate, chloroform, and acetone compared to hexane and methanol may be due to the differences in the type of active constituents present in the extracts (Jeyaseelan et al., 2012).

Lack of activity in water extracted samples could have resulted from the hydrolytic effect of water-hydrolysis of particularly saponins. A known larvicidal compound yields saprogenic and corresponding glycosides with loss of activity. Saponin also hydrolyzes with time, and so the longer the duration of extraction of saponin, the higher the hydrolysis. On the other hand, tannins, flavonoids, terpenes, and some saponins are most difficult to be dissolved in water but more easily extractable with methanol (Sakagami et al., 2012). According to Olugbenga et al. (2012), methanol is a better solvent for saponin than water. Several tannins, including hydrolyzable geranin, are also unstable in water. Organic plant extracts were found to give more consistent antimicrobial activity than water extracts. Also, water-soluble flavonoids, mostly anthocyanins, have no significant antimicrobial activity, and water-soluble phenolics are only crucial as antioxidant compounds (Das et al., 2010).

The Tukey post hoc tests indicated that after $24 \mathrm{~h}$, the mortality rate for $V$. galamensis (mean $=7.73$ ) was significantly different from that of $V$. lasiopus (mean $=$ $5.29)$ and $V$. auriculifera $($ mean $=5.57)$. It is evident that $V$. galamensis showed the highest total mean mortality making it the most promising plant. The results were also confirmed by the results of the probit analysis that indicated that $V$. galamensis recorded low $\mathrm{LC}_{50}$ values in some extracts, which included acetone root extract (22.85), acetone leaf extract (62.61), and ethyl acetate root extract (68.24). Vernonia auriculifera and V. lasiopus recorded the highest activities in acetone root extract, and ethyl acetate root extracts with an $\mathrm{LC}_{50}$ value of 37.7 and 205.9, respectively.

Results in (Table 9) confirm that root extracts were more potent than the leaf extracts. The effective concentration for $V$. auriculifera root extracts and $V$. lasiopus root extracts were $1000 \mathrm{ppm}$. On the other hand, the active concentration for $V$. galamensis root extracts was 500 ppm and above. Vernonia lasiopus leaf extracts recorded a sufficient concentration of 1000 ppm. However, $V$. galamensis and $V$. auriculifera leaf extracts did not have effective levels ranging between 125 ppm and 1000 ppm.

The larval stage is regarded as the most vulnerable stage to attack mosquitoes as they are concentrated in small areas. One of the approaches for controlling malaria transmission is interrupting the mosquito life cycle at the larval stage (Srivastava et al., 2008). The finding obtained in this study confirms the potential of extracts from $\mathrm{V}$. galamensis, V. lasiopus, and V. auriculifera to control the larval population of $A$. gambiae.

\section{Conclusions}

The leaves and roots of $V$. lasiopus, $V$. auriculifera, and $V$. galamensis contain active insecticidal compounds, including steroids, flavonoids, cardiac glycosides, terpenoids, tannins, and saponins. All of the three species 
possess larvicidal activity against A. gambiae, with $V$. galamensis exhibiting the highest total mean mortality (mean $=7.73)$, making it the most potent plant compared to $V$. lasiopus $($ mean $=5.29)$ and $V$. auriculifera $($ mean $=$ 5.57) after 24 hours. The result was also confirmed by the data of the probit analysis, which indicated that $V$. galamensis recorded low LC50 values in some extracts that included acetone root extract, acetone leaf extract, and ethyl acetate root extract. Vernonia auriculifera and $V$. lasiopus recorded the highest activities in acetone root extract, and ethyl acetate root extracts with an LC50 value of 37.7 and 205.9, respectively. The finding from this study indicates that the root extracts were more potent than the leaf extracts. The effective concentration for $V$. auriculifera root extracts and $V$. lasiopus root extracts were 1000 ppm. Meanwhile, the effective concentration for $V$. galamensis root extracts was from 500 ppm and above. Vernonia lasiopus leaf extracts recorded an adequate concentration of $1000 \mathrm{ppm}$. However, from the concentration tested in this study that falls between 125 ppm and $1000 \mathrm{ppm}$, neither $V$. galamensis nor $V$. auriculifera leaf extracts showed effectiveness against $A$. gambiae. Vernonia lasiopus, $V$. auriculifera, and $V$. galamensis can be used to develop newer, more selective, and biodegradable larvicide as an alternative to the rather expensive and environmentally hazardous inorganic insecticides. Further work to determine what secondary metabolites in Vernonia extracts are responsible for the larvicidal activity is of future interest.

\section{REFERENCES}

Albuquerque MRJR, Costa SMO, Bandeira PN, Santiago GMP, AndredeNeto M, Silveiria ER, Pessoa ODL. 2007. Nematicidal, larvicidal activities of Pectis oligocephala and Pectis apodocephala Baker. Anais da Academia Brasileira de Ciencias 79 (2): 209-213. DOI: 10.1590/S0001-37652007000200003

Bayavan A, Rahuman AA, Kamaraj C, Kannappan G. 2008. Larvicidal activity of a saponin from Achyranthes aspera against Aedes aegypti and Culex quinquefasciatus. Parasitol Res 103: 1223-1229. DOI: 10.1007/s00436-008-0962-z.

Bell D, Wongsrichanalai C, Barnwell JW. 2006. Ensuring quality and access for malaria diagnosis: how can it be achieved? Nat Rev Microbiol 4 (9): S7-S20. DOI: 10.1038/nrmicro1525.

Benjon P, White MT, Olotu A, Bojang K, Lusingu JPA, Salim N, Otsyula N, Agnandji ST, Asante SO, Abdulla S, Ghani AC. 2013. Efficacy of RTS, S malaria vaccines: Individual-participant pooled analysis of phase 2 data. Lancet Infect Dis 13: 319-327. DOI: 10.1016/S1473 3099(13)70005-7.

Bockarie JM. 2005. Biology of Disease Vectors. 2nd ed. Am J Trop Med Hygiene 73: 1167. DOI: 10.4269/ajtmh.2005.73.1167.

Borah R, Kalita MC, Kar A, Talukdar AK. 2010. Larvicidal efficacy of Toddalia asiatica (Linn.) Lam against two mosquito vectors, Aedes aegypti and Culex quinquefasciatus. Afr J Biotechnol 9 (17): 2527 2530.

Brown AE. 2006. Mode of action of insecticides and related pest control chemicals for production agriculture, ornamentals and turf. Pestic Educ Assess Programs 301: 405-3913.

Chowdhury N, Ghosh A, Chandra G. 2008. Mosquito larvicidal activities of Solanum villosum berry extract against the dengue vector
Stegomyia aegypti. BMC Compl Altern Med 8 (1): 1-8. DOI: 10.1186/1472-6882-8-10. DOI: 10.1186/1472-6882-8-10.

Das K, Tiwari RKS, Shrivastava DK. 2010. Techniques for evaluation of medicinal plant products as antimicrobial agent: Current methods and future trends. J Med Plants Res 4 (2): 104-111.

Das S, Garver L, Dimopoulos G. 2007. Protocol for mosquitoe rearing ( $A$. gambiae). J Visualised Exp 5: 221. DOI: 10.3791/221.

Diallo D, Marston A, Terreaux C, Touré Y, Paulsen BS, Hostettmann K. 2001. Screening of Malian medicinal plants for antifungal, larvicidal, molluscicidal, antioxidant, and radical scavenging activities. Phytotherapy Res 15 (5): 401-406. DOI: 10.1002/ptr.738.

Elsheikha HM, Khan NA. 2011. Essentials of Veterinary Parasitology. Caister Academic Press, Poole, UK.

Finney DJ. 1971. Probit Analysis. 3rd ed. Cambridge University Press, London, UK.

Jeyaseelan EC, Vinuja T, Pathmanathan K, Jeyadevan J.P. 2012. Control of plant pathogenic fungi using organic solvent extracts of leaf, flower, and fruit of Lawsonia inermis L. Intl J Pharmaceut Biol Arch 3 (4): 783-788.

Kalu IG, Ofoegbu U, Eroegbusi J, Nwachukwu CU, Ibeh B. 2010. Larvicidal activities of ethanol extracts of Allium sativum (garlic bulb) against the filarial vector, Culex quinquefasciantus. J Med Plants Res 4 (6): 496-498.

Kokwaro JO. 2009. Medicinal Plants of East Africa. 3rd ed. University of Nairobi Press, Nairobi.

Macedo ME, Consoli RAGB, Grandi SM, Dos Anjos M .G, Oliera BA, Mendes AN, Queiroz OR, Zani LC. 1997. Screening of Asteraceae (Compositae) plant extracts for larvicidal activity against Aedes fluviatilis (Dipthera: Culicidae). Memórias do Instituto Oswald Cruz. Rio de Janeiro 92: 565-570. DOI: 10.1590/S007402761997000400024

Magadula JJ, Erasto P. 2009. Bioactive natural products derived from the East African flora. Nat Prod Rep 26 (12): 1535-1554. DOI: 10.1039/b906089h

Matasyoh JC, Wathuka EM, Kariuki ST, Chepkorir R, Kavulani J. 2008. Aloe plant extracts as alternative larvicides for mosquito control. Afr J Biotechnol 7 (7): 912-915.

Mohamed LT, El Nur BS, Abdelrahman MN. 2010. The antibacterial, antiviral activities, and phytochemical screening of some Sudanese medicinal plants. EurAsia J Biosci 4: 8-16. DOI: 10.5053/ejobios.2010.4.0.2

Olugbenga AM, Musa AH, Olwatoyin AH. 2012. Toxicological activity of crude saponin extract of Ficus platyphylla. Asian J Pharmaceut Clin Res 5 (1): 30-33.

Oyen LPA. 2010. Vernonia auriculifera Hiern. In: Brink M, AchiganDako EG (eds) Prota 16: Fibres. PROTA, Wageningen, Netherlands.

PMI. 2014. Kenya Malarial Operational Plan FY 2014. President's Malaria Initiative, Government of Kenya and USA, Washington, DC.

Sakagami H, Kushida T, Makino T, Hatano T, Shirataki Y, Matsuta T, Matsuo Y, Mimaki Y. 2012. Functional Analysis of Natural Polyphenols and Saponins as alternative Medicine. In: Bhattacharya A (ed) A Compendium of Essays on Alternative Therapy. InTech, Rijeka, Croatia. DOI: 10.5772/30449.

Sofowora A. 1993. Medicinal Plants and Traditional Medicine in Africa. Spectrum Books Ltd., Ibadan, Nigeria.

Srivastava A, Bartarya R, Tonk S, Srivastava SS, Kumari M. 2008. Larvicidal activity of an Indigenous plant, Centratherum anthelmintcum. J Environ Biol 29 (5): 669-672.

Srivastava N, Patel T. 2007. Clerodendrum and healthcare: An overviewpart II phytochemistry and biotechnology. Med Aromat Plant Sci Biotechnol 1 (2): 209-223.

Trease GE, Evans WC. 2002. Pharmacolognsy. 15 $15^{\text {th }}$ ed. Saunders Publishers, London, UK.

WHO. 1981. Instructions for determining susceptibility of resistance of mosquito larvae to insecticides. WHO/VBC-81. World Health Organization, Geneva.

WHO. 2010. Malaria Fact sheet No. 94, April 2010. World Health Organization, Geneva. 